\title{
Gene expression changes in Porphyromonas gingivalis W83 after inoculation in rat oral cavity
}

\author{
Jian Zhao, Qian Li, Chun-Ling Pan, Jun-Chao Liu, Hong-Yan Wang, Li-Si Tan and Ya-Ping Pan*
}

\begin{abstract}
Background: The development of chronic periodontitis was due to not only periodontal pathogens, but also the interaction between periodontal pathogens and host. The aim of this study is to investigate the alterations in gene expression in Porphyromonas gingivalis (P.gingivalis) W83 after inoculation in rat oral cavity.

Results: P.gingivalis W83 inoculation in rat oral cavity caused inflammatory responses in gingival tissues and destroyed host alveolar bone. Microarray analysis revealed that 42 genes were upregulated, and 22 genes were downregulated in the detected 1786 genes in the inoculated P.gingivalis W83. Real-time quantitative PCR detection confirmed the expression alterations in some selected genes. Products of these upregulated and downregulated genes are mainly related to transposon functions, cell transmembrane transportation, protein and nucleic acid metabolism, energy metabolism, cell division and bacterial pathogenicity.

Conclusions: P.gingivalis W83 has a pathogenic effect on host oral cavity. Meanwhile, inflammatory oral environment alters P.gingivalis W83 gene expression profile. These changes in gene expression may limit the proliferation and weaken the pathogenicity of P.gingivalis W83, and favor themselves to adapt local environment for survival.
\end{abstract}

Keywords: Porphyromonas gingivalis, Periodontitis, Microarray, Gene expression

\section{Background}

Periodontitis is a chronic inflammatory disorder mediated by host and bacteria interactions and manifested by damage to the periodontal tissues that may progress to tooth loss. The host inflammatory responses stimulated by periodontal pathogens intend to eliminate the invaded bacteria and attribute to the destruction of tooth supporting tissues and tooth loss [1]. Moreover, the local periodontal environment may change the gene expression profile of periodontal pathogens [2-4]. To a certain extent, the variation of bacterial gene expression may alter the pathogenic ability of bacteria.

Porphyromonas gingivalis (P.gingivalis) is an opportunistic pathogen of the oral mucosa and a prominent member of the oral biofilms. It is well known that P.gingivalis is implicated in the onset and progression of chronic periodontitis. P.gingivalis can induce immune cells to secrete cytokines when they invade into hosts. These cytokines are present in inflamed gingiva and aggravate the destruction of oral gingival tissues and alveolar bone [5]. In the

\footnotetext{
* Correspondence: yppan@mail.cmu.edu.cn

Department of Periodontology, School of Stomatology, China Medical University, Shenyang, Liaoning, China
}

(c) 2015 Zhao et al.; licensee BioMed Central. This is an Open Access article distributed under the terms of the Creative Commons Attribution License (http://creativecommons.org/licenses/by/4.0), which permits unrestricted use, distribution, and reproduction in any medium, provided the original work is properly credited. The Creative Commons Public Domain Dedication waiver (http://creativecommons.org/publicdomain/zero/1.0/) applies to the data made available in this article unless otherwise stated.

\section{Methods}

Ethical statement

All rats were manipulated in accordance with Animal Research Reporting In Vivo Experiments (ARRIVE) guidelines. The experimental protocols were approved by the ethical committee of China Medical University.

meantime, the expression of P.gingivalis genes varies under different conditions, such as iron or hemin [6,7], yphosphate [8], rhein [9]. P.gingivalis may up-regulate ownregulate gene expression to adapt environment

The development of chronic periodontitis was not only due to periodontal pathogens, but also the interaction but ignore the action of host on P.gingivalis. Actually, the changes in P.gingivalis gene expression may affect experiont W83 inoculated in W83 inoculated in rat oral cavity and wild strain was analyzed.

uns otherwise stated. 


\section{Bacteria and animals}

This study was carried out with 6-week-old SPF rats $(180-220$ g) provided by Department of Experimental Animals, China Medical University, and maintained in a temperature-controlled room $\left(23 \pm 1{ }^{\circ} \mathrm{C}\right)$. P.gingivalis W83 was obtained from the American Type Culture Collection (ATCC) and grown anaerobically $\left(10 \% \mathrm{CO}_{2}\right.$, $10 \% \mathrm{H}_{2}, 80 \% \mathrm{~N}_{2}$ ) in enriched brain-heart infusion (BHI) broth containing $5 \%$ fiber-free sheep blood, $1 \%$ vitamin $\mathrm{K}$ and hemin, at $37^{\circ} \mathrm{C}$.

\section{P.gingivalis W83 inoculation}

12 Rats were given azithromycin $(10 \mathrm{mg} / 500 \mathrm{ml})$ ad libitum for 4 days to reduce the original oral flora. This was followed by a 7-day antibiotic-free period. 6 Rats were then orally challenged with $P$. gingivalis W83 $\left(1 \times 10^{9} \mathrm{CFU}\right)$ by gavage into the esophagus and oral cavity five times every other day [11]. The other 6 rats (control group) were only challenged with BHI broth. All 12 rats received steel wire ligature in cervical part in two sides of first molars and an 8-week high sugar feeding.

\section{Alveolar bone loss analysis}

Horizontal bone loss was assessed morphometrically by measuring the distance between the cement-enamel junction and the alveolar bone crest of the first, the second and the third molar. The alveolar bone destruction was detected by morphological and macroscopic observation, radiographic (PLANMECA, Finland) and stereomicroscope (SZX12, Olympus, Japan) fitted with a DIGIMED Viewer imaging measurement system evaluation at 6 sites per molars. Alveolar bone loss of every molar was presented in the figures as mean \pm SD. Independent samples $t$-test was used to calculate the significance among the groups (SPSS Inc., Chicago, IL, USA). $P$-value $<0.05$ was considered statistically significant.

\section{Isolating culture and acquiring plaque}

After P.gingivalis W83 inoculation in rat oral cavity for 8 weeks, plaques were acquired from periodontal pockets of first molar using toothpicks and put into $0.5 \mathrm{ml}$ transfer tube. The plaques were dispersed by oscillator. $100 \mu \mathrm{l}$ ten-fold serial dilutions were inoculated on BHI culture medium anaerobically at $37{ }^{\circ} \mathrm{C}$ for $5-7$ days. The morphology of colonies was observed in primary cultures. P.gingivalis W83 colonies were identified by their black pigmentation, gram staining and PCR. The single clone was purified in BHI medium for subcultures in order to detect the differences in the gene of P.gingivalis W83.

\section{Microarray hybridization}

3 samples were picked up from wild strain P.gingivalis W83 and inoculated P.gingivalis W83, respectively. The total RNA was extracted and labeled with Klenow, and then hybridism with P.gingivalis W83 chip. The commercial GeneChip P.gingivalis W83 Genome Array used here was provided by CapitalBio Corporation (http:// www.capitalbio.com/, Beijing, China), a service provider authorized by Roche NimbleGen (Wisconsin, USA). Array hybridization, washing, scanning and data analysis were performed at the CapitalBio Corporation, Beijing, China and carried out according to the NimbleGen's Expression user's guide.

\section{Real-time quantitative PCR}

To independently confirm the expression data generated by the microarray experiments, we performed real-time quantitative PCR analyses for 14 genes differentially regulated. Total RNA was extracted. Quality and concentration of the RNA were determined by measuring its absorbance at 260 and $280 \mathrm{~nm}$ using a microplate reader (M-200, Tecan, Switzerland). Total bacterial RNA was subsequently reverse-transcribed using the M-MLV RTase cDNA Synthesis Kit (Takara, China) following the manufacturer's protocol. Real-time quantitative PCR analysis was conducted in an ABI Prism 7500 Sequence Detection System (Applied Biosystems, Foster City, CA, USA) in combination with the SYBR ${ }^{\bullet}$ Premix Ex TaqTM II PCR Master Mix Reagents Kit (Takara), as recommended by the manufacturer of the Wall Clear PCR Strip Tubes (Axygen, USA). The primers for the real-time quantitative PCR analysis were designed using Primer3 (http://bioinfo.ut.ee/primer3/) (Table 1). P.gingivalis W83 16 s DNA was used as the internal reference. Real-time quantitative PCR was performed three times for each sample. The data were analyzed according to relative gene expression by the $2-{ }^{\Delta \Delta} \mathrm{Ct}$ method.

\section{Statistics}

Significantly differentially expressed genes between the inoculated periodontitis and wild strains were identified using two class unpaired method in the Significant Analysis of Microarray software (SAM, version 3.02). Genes were determined to be significantly differentially expressed with a selection threshold of false discovery rate, FDR $<5 \%$ and fold change $>2.0$ in the SAM output result.

\section{Results}

Pathogenic effects of P.gingivalis W83 on rat oral cavity

After P.gingivalis W83 inoculation in rat oral cavity for 8 weeks, the gingival tissues were inflammatory and bleeding (Fig. 1A). Severe alveolar bone losses were found in rats with P.gingivalis W83 inoculation (Fig. 1B). The distance between cementoenamel junction and alveolar bone crest (CEJ: ABC) was measured at proximal, middle and distal sites of buccal and palatal per molar, respectively. In first molars, second 
Table 1 Sequences for real-time PCR

\begin{tabular}{|c|c|c|}
\hline Gene & Sequence $\left(5^{\prime}-3^{\prime}\right)$ & PCR product (bp) \\
\hline \multirow[t]{2}{*}{ PG1005 } & F: CGGTGAGGTTACAGAAGAA & 79 \\
\hline & R: AGGGAGGTGTAAGTCACG & \\
\hline \multirow[t]{2}{*}{ PG1006 } & F: GGAATGGAGCGAAAGACC & 169 \\
\hline & R: CCAACAAGCAGAACCGAC & \\
\hline \multirow[t]{2}{*}{ PG1007 } & F: TCTGTTTGTTGTCCCATTC & 62 \\
\hline & R: TATGGCTCCTCAAAGTAGAG & \\
\hline \multirow[t]{2}{*}{ PG1008 } & F: TTACAACAGCGGCTACCA & 103 \\
\hline & R: TATCCACTGCCACAGCCT & \\
\hline \multirow[t]{2}{*}{ PG1009 } & F: AAGCGTGCTACCATTGCG & 78 \\
\hline & R: TCAGGCTATACCCGTTCT & \\
\hline \multirow[t]{2}{*}{ PG1010 } & F: TCTGTCCCTGCGATACCT & 99 \\
\hline & R: CACTCATCCTCCCTATCTITC & \\
\hline \multirow[t]{2}{*}{ PG0874 } & F: AGGGTGTCTGAGCAAGTA & 73 \\
\hline & R: TGGAGGAATCGAAGATAGAA & \\
\hline \multirow[t]{2}{*}{ PG1513 } & F: GAAACGGCTCAAGTCATA & 114 \\
\hline & R: TCCСТCСТCCATTTCCAC & \\
\hline \multirow[t]{2}{*}{ PG0684 } & F: GAATACGGAGGTCAATCGC & 90 \\
\hline & R: GAACGCTGAGAAGGAGGC & \\
\hline \multirow[t]{2}{*}{ PG0682 } & F: CGGTGAGTTCTATTATTGCG & 123 \\
\hline & R: CAGCACCAGGCATGACCA & \\
\hline \multirow[t]{2}{*}{ PG1975 } & F: CGTGACGGGCATAAGACA & 134 \\
\hline & R: AGTGAGTCGTGGGTTTAC & \\
\hline \multirow[t]{2}{*}{ PG1982 } & F: GTAATACCGAGGAAACTGAA & 60 \\
\hline & R: GTGTTTCAGGGATAAGTCG & \\
\hline \multirow[t]{2}{*}{ PG2008 } & F: CTGCGGTTTCAACCAAGT & 115 \\
\hline & R: ATACCGAACCTCGTCTAC & \\
\hline \multirow[t]{2}{*}{ PG0001 } & F: AGGTGGTCATGTTCCTCTCC & 78 \\
\hline & R: TGACTACCCTCCTGCATTGG & \\
\hline
\end{tabular}

molars, third molars, the distances were significantly increased, which were $1216.00 \pm 305.98 \mu \mathrm{m}, 987.28 \pm$ $238.14 \mu \mathrm{m}, 725.11 \pm 202.71 \mu \mathrm{m}$, compared with normal rats, which were $414.89 \pm 209.67 \mu \mathrm{m}, 300.44 \pm 127.92 \mu \mathrm{m}$, $357.56 \pm 281.06 \mu \mathrm{m}$.

\section{Identification of the inoculated P.gingivalis W83 in rat with periodontitis}

Suspicious gram-negative bacilli were taken from plaque culture. After pure subculture, gram staining and polymerase chain reaction (PCR) proved that the bacteria were P.gingivalis W83. PCR fragment length of the product was $857 \mathrm{bp}$, as shown in Fig. 2.

\section{Genes upregulated in the inoculated P.gingivalis W83}

We determined the expression of 1786 genes by microarray analysis in P.gingivalis wild strain and P.gingivalis inoculated in oral cavity. The complete list of gene expression values has been deposited in NCBI's Gene Expression Omnibus (http://www.ncbi.nlm.nih.gov/geo/ query/acc.cgi?acc=GSE67608). The detection showed that 42 genes were up-regulated in the inoculated P.gingivalis W83 compared with wild strain (Table 2) (Fig. 3). In these upregulated genes, 30 expressed hypothetical proteins. Among other 12 genes, PG0874, PG0009, PG0427, PG0942 and PG0590 function as transposons. PG0009, PG0427, PG0942 and PG0590 encode ISPg5 transposases; and PG0874 encodes an int protein as a mobilizable transposon.

\section{Genes downregulated in the inoculated P.gingivalis W83}

Compared with wild strain, 22 genes were downregulated in the inoculated strain (Table 3) (Fig. 3). Among these genes, PG0682, PG0683, PG0684, PG0282 and PG0946 encode ABC transporters. Products of PG0682, PG0683 and PG0684 are putative permease proteins; and products of PG0282 and PG0946 are ATPbinding proteins. In addition, PG2008 and PG0283 also encode transport and binding proteins. All these proteins are involved in cell transmembrane transportation. Some downregulated genes encode proteins related to protein and nucleic acid metabolism, including PG1129, PG1993, PG0001 and PG0522. Products of other genes are related to energy metabolism (PG1042), cell division (PG0141),bacterial pathogenicity (PG1975), and so on.

Microarray result confirmation by real-time quantitative PCR Among the upregulated and downregulated genes, we picked up 14 genes to detect the expression by realtime quantitative PCR. Consistent with microarray hybridization, real-time quantitative PCR detection showed similar expression trends in these genes (Table 4).

\section{Discussion}

Chronic periodontitis is initiated by periodontal pathogens, including P.gingivalis. Our study showed that P.gingivalis W83 induced rat gingival tissue inflammation, and alveolar bone loss, which is the key feature of periodontitis. Therefore, our study demonstrates that P.gingivalis W83 has pathogenic effects on rat oral cavity. After inoculation in rat oral cavity for 8 weeks, P.gingivalis W83 were isolated, and analyzed by microarray. In the detected 1786 genes, 42 genes were upregulated, whereas 22 genes were downregulated, indicating that the local periodontal environment can change the gene expression profile of P.gingivalis W83.

In the 42 upregulated genes, 30 expressed hypothetical proteins. Among other 12 genes, PG0874, PG0009, PG0427, PG0942 and PG0590 are in the same class in JCVI cell function classification. They all function as mobile extrachromosomal factor: transposon. Transposon 


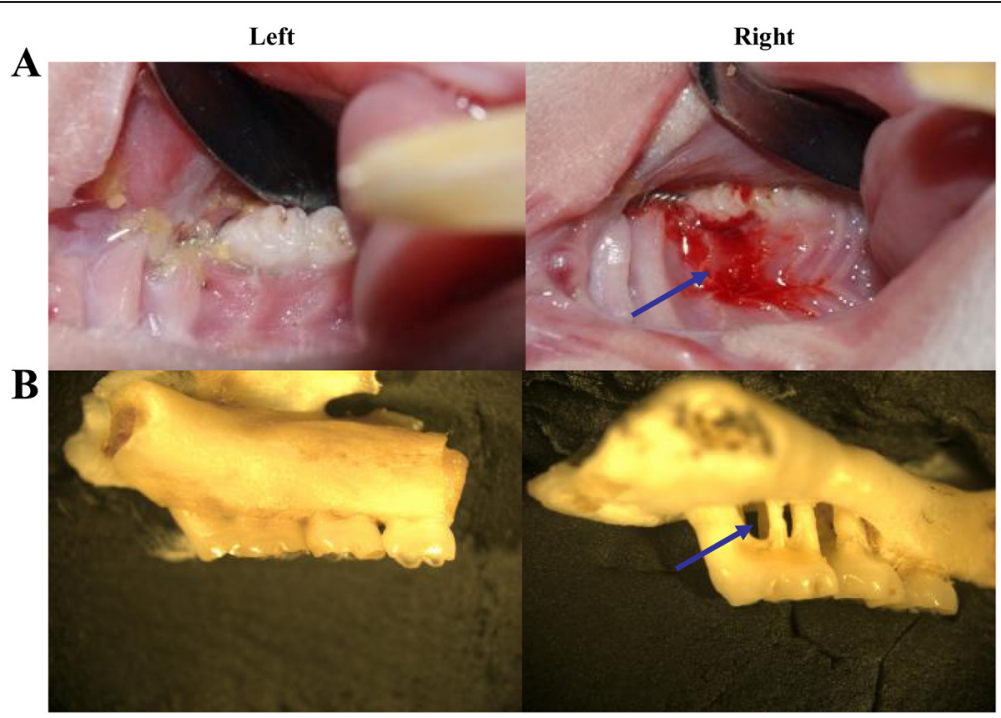

Fig. 1 Pathogenic effects of P.gingivalis W83 on rat oral cavity. (A) The gingival tissues were inflammatory and bleeding after P.gingivalis W83 inoculation in rat oral cavity for 8 weeks. (B) Severe alveolar bone losses were found in rats with P.gingivalis W83 inoculation. Left: control groups. Right: rats inoculated with P.gingivalis W83 intraorally for 8 weeks

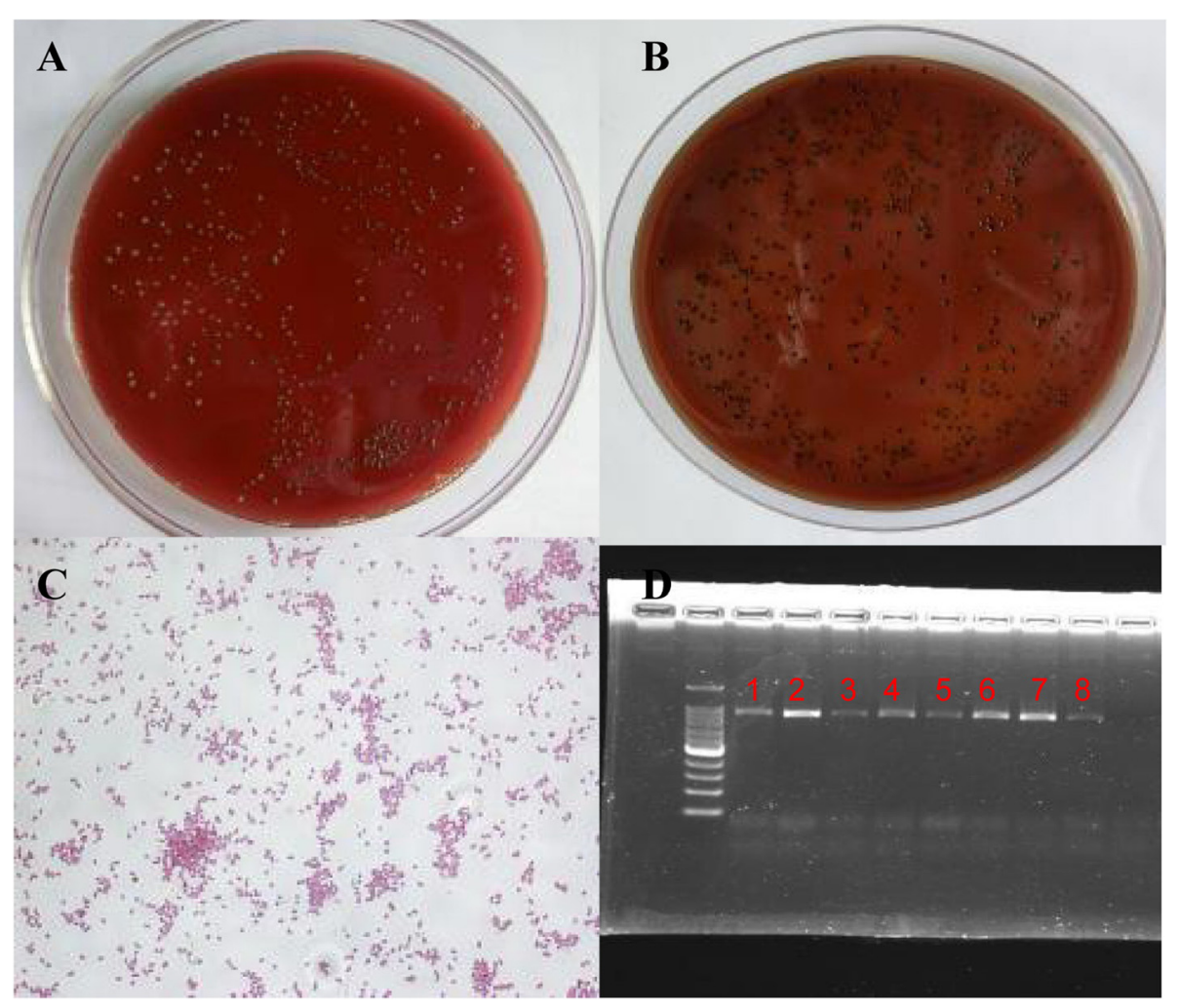

Fig. 2 Isolation and identification of inoculated P.gingivalis W83. (A) Some suspicious black colonies were found from plaque mixture. (B) Suspious black colonies were pure cultured. (C) Gram staining proved the pure culture as gram-negative brevibacterium ( $\times 400)$. (D) Agarose gel electrophoresis proved that PCR fragment length was 857 bp. 1 and 2: Wild type P.gingivalis W83; 3-8: three inoculated P.gingivalis W83 samples for microarray analysis (two columns for each sample) 
Table 2 Genes upregulated in the inoculated P.gingivalis W83

\begin{tabular}{|c|c|c|c|}
\hline Locus no. & Putative identification $^{\alpha}$ & Cellular role ${ }^{a}$ & Fold \\
\hline PG0102 & hypothetical protein & & 3.7076 \\
\hline PG2116 & hypothetical protein & & 3.6850 \\
\hline PG1007 & GntR family transcriptional regulator & Regulatory functions: DNA interactions & 3.6786 \\
\hline PG0265 & hypothetical protein & & 3.3714 \\
\hline PG1008 & hypothetical protein & & 3.3338 \\
\hline PG1510 & hypothetical protein & & 3.0890 \\
\hline PG1009 & hypothetical protein & & 3.0258 \\
\hline PG1655 & hypothetical protein & & 2.8935 \\
\hline PG0132 & hypothetical protein & & 2.7298 \\
\hline PG2114 & hypothetical protein & & 2.6986 \\
\hline PG2064 & hypothetical protein & & 2.5952 \\
\hline PG1010 & ABC transporter, ATP-binding protein & Transport and binding proteins: Unknown substrate & 2.4885 \\
\hline PG0542 & hypothetical protein & & 2.4794 \\
\hline PG1005 & putative lipoprotein & Cell envelope & 2.4686 \\
\hline PG1514 & glycerol dehydrogenase-related protein & Unknown function: General & 2.4537 \\
\hline PG0844 & hypothetical protein & & 2.4324 \\
\hline PG0874 & mobilizable transposon, int protein & $\begin{array}{l}\text { Mobile and extrachromosomal element functions: } \\
\text { Transposon functions }\end{array}$ & 2.4307 \\
\hline PG0507 & hypothetical protein & & 2.4290 \\
\hline PG1357 & hypothetical protein & & 2.3151 \\
\hline PG1410 & hypothetical protein & & 2.3094 \\
\hline PG0617 & hypothetical protein & & 2.2814 \\
\hline PG0855 & hypothetical protein & & 2.2153 \\
\hline PG0009 & ISPg5, transposase Orf1 & $\begin{array}{l}\text { Mobile and extrachromosomal element functions: } \\
\text { Transposon functions }\end{array}$ & 2.1609 \\
\hline PG0427 & ISPg5, transposase Orf1 & $\begin{array}{l}\text { Mobile and extrachromosomal element functions: } \\
\text { Transposon functions }\end{array}$ & 2.1431 \\
\hline PG0942 & ISPg5, transposase Orf1 & $\begin{array}{l}\text { Mobile and extrachromosomal element functions: } \\
\text { Transposon functions }\end{array}$ & 2.1424 \\
\hline PG0541 & hypothetical protein & & 2.1291 \\
\hline PG1398 & hypothetical protein & & 2.1216 \\
\hline PG1027 & hypothetical protein & & 2.1204 \\
\hline PG0590 & ISPg5, transposase Orf1 & $\begin{array}{l}\text { Mobile and extrachromosomal element functions: } \\
\text { Transposon functions }\end{array}$ & 2.1151 \\
\hline PG1006 & hypothetical protein & & 2.1122 \\
\hline PG0340 & hypothetical protein & & 2.1119 \\
\hline PG0256 & CvpA family protein & Unknown function: General & 2.1090 \\
\hline PG0749 & hypothetical protein & & 2.0834 \\
\hline PG1662 & hypothetical protein & & 2.0788 \\
\hline PG2220 & hypothetical protein & & 2.0771 \\
\hline PG1871 & hypothetical protein & & 2.0589 \\
\hline PG2187 & 1,4-dihydroxy-2-naphthoate octaprenyltransferase & $\begin{array}{l}\text { Biosynthesis of cofactors, prosthetic groups, and carriers: } \\
\text { Menaquinone and ubiquinone }\end{array}$ & 2.0471 \\
\hline PG0410 & hypothetical protein & & 2.0409 \\
\hline PG1233 & hypothetical protein & & 2.0367 \\
\hline PG0325 & hypothetical protein & & 2.0349 \\
\hline
\end{tabular}


Table 2 Genes upregulated in the inoculated P.gingivalis W83 (Continued)

\begin{tabular}{llll}
\hline PG0409 & $\begin{array}{l}\text { hypothetical protein } \\
\text { phosphoribosyltransferase, putative/phosphoglycerate }\end{array}$ & Energy metabolism: Other & 2.0259 \\
PG1513 & mutase family protein & 2.0032 \\
\hline
\end{tabular}

aLocus number, identification and functional classification according to JCVI P.gingivalis genome database

is a removable genome DNA sequence, which can "jump" in genome from one location to another through the process of cutting and integration. Transposition is generally known to be triggered by cellular stress [12-14], therefore upregulation of these transposons suggests that P.gingivalis W83 inoculated in rat oral cavity may adapt local environment for its own survival, which is consistent with some other studies $[15,16]$.

In the 22 downregulated genes, 7 genes encode transport and binding proteins. All these proteins are involved in cell transmembrane transportation. They can transport many substrates, such as metabolites, ion, sugar, amino acids, lipids, cholesterol and drugs [17]. PG2008 encodes a TonB dependent receptor protein, responsible for iron transmembrane transportation [18]. As iron ion is necessary for the breeding and spreading of P.gingivalis W83, downregulation of PG2008 suggests the subdued iron transferring and proliferation of P.gingivalis W83. There are 4 downregulated genes encoding proteins related to nucleic acid and protein metabolism. PG1129 encodes a nucleotide reductase, which is related to purine, pyrimidine, nucleotide and DNA metabolism, and plays a regulating role in cell proliferation. Products of PG1993 and PG0001 are related to the metabolism of DNA, such as copy, restructuring and repair. Therefore, downregulation of these genes means that the proliferation of inoculated P.gingivalis W83 is in certain obstacles.

PG1042 encodes a putative glycogen synthase, involved in biosynthesis and degradation of polysaccharides. Downregulation of PG1042 suggests a disturbed energy metabolism. PG0141 encodes a spoOJ protein related to

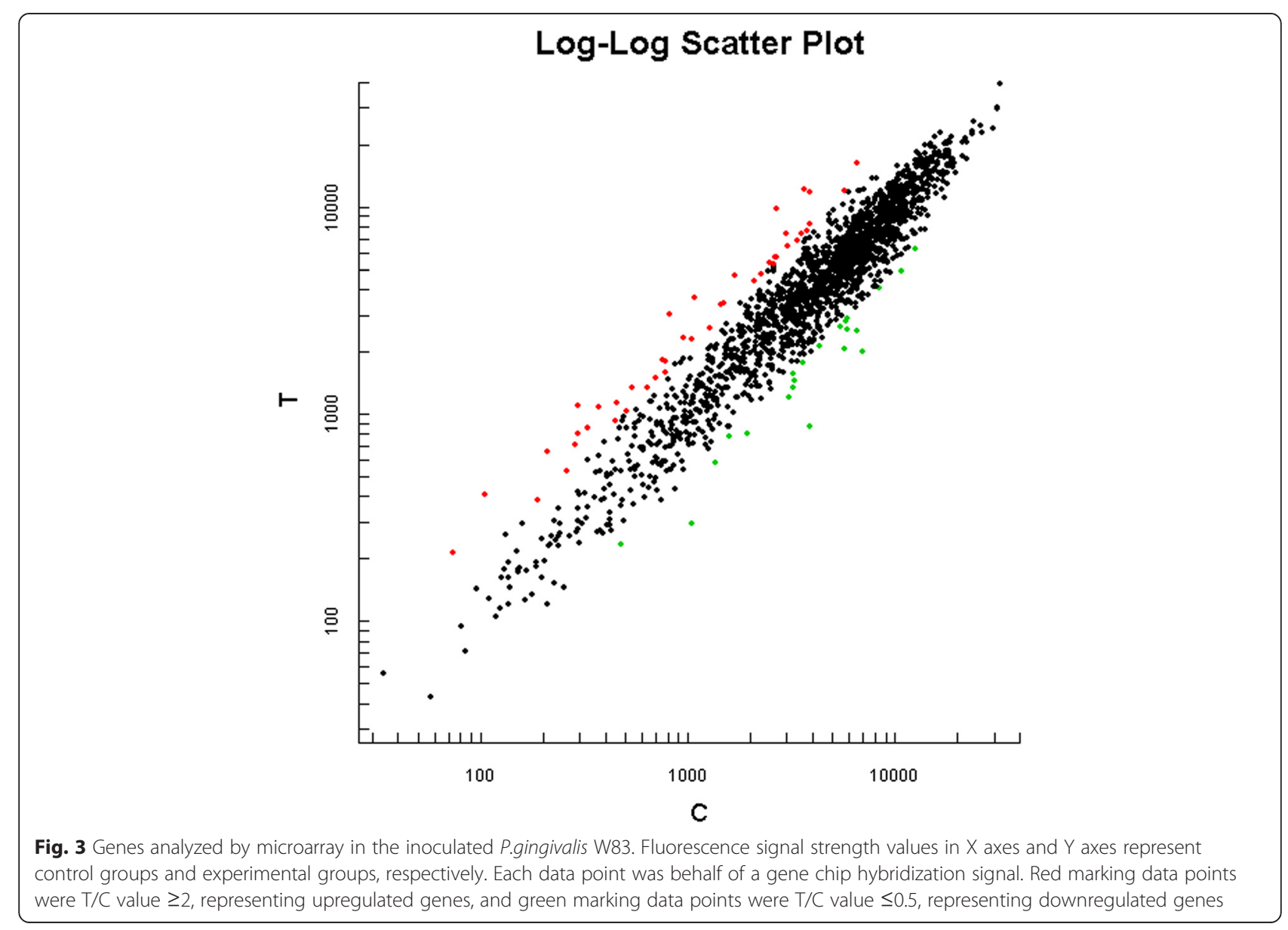


Table 3 Genes downregulated in the inoculated P.gingivalis W83

\begin{tabular}{|c|c|c|c|}
\hline Locus no. & Putative identification $^{\alpha}$ & Cellular role ${ }^{\alpha}$ & Fold \\
\hline PG2008 & TonB-dependent receptor, putative & Transport and binding proteins: Cations and iron carrying compounds & 0.2234 \\
\hline PG0929 & hypothetical protein & & 0.2806 \\
\hline PG1129 & ribonucleotide reductase & $\begin{array}{l}\text { Purines, pyrimidines, nucleosides, and nucleotides: } \\
\text { 2'-Deoxyribonucleotide metabolism }\end{array}$ & 0.2862 \\
\hline PG0684 & ABC transporter, permease protein, putative & Transport and binding proteins: Unknown substrate & 0.3594 \\
\hline PG0683 & $A B C$ transporter, permease protein, putative & Transport and binding proteins: Unknown substrate & 0.3848 \\
\hline PG0682 & ABC transporter, permease protein, putative & Transport and binding proteins: Unknown substrate & 0.3938 \\
\hline PG0522 & tRNA delta(2)-isopentenylpyrophosphate transferase & Protein synthesis: tRNA and rRNA base modification & 0.4190 \\
\hline PG1648 & RelA/SpoT family protein & Cellular processes: Adaptations to atypical conditions & 0.4192 \\
\hline PG0282 & ABC transporter, ATP-binding protein & Transport and binding proteins: Unknown substrate & 0.4303 \\
\hline PG0946 & ABC transporter, ATP-binding protein & Transport and binding proteins: Unknown substrate & 0.4347 \\
\hline PG1042 & glycogen synthase, putative & Energy metabolism: Biosynthesis and degradation of polysaccharides & 0.4485 \\
\hline PG0890 & alkaline phosphatase, putative & Central intermediary metabolism: Other & 0.4552 \\
\hline PG1100 & hypothetical protein & & 0.4813 \\
\hline PG1993 & excinuclease $A B C$ subunit $C$ & DNA metabolism: DNA replication, recombination, and repair & 0.4814 \\
\hline PG0226 & transglutaminase-related protein & Unknown function: General & 0.4823 \\
\hline PG0141 & spoOJ protein & Cellular processes: Cell division & 0.4865 \\
\hline PG0144 & hypothetical protein & & 0.4888 \\
\hline PG1975 & hemagglutinin protein $\mathrm{HagC}$ & Cellular processes: Pathogenesis & 0.4941 \\
\hline PG1982 & CRISPR-associated Cas1 family protein & Mobile and extrachromosomal element functions: Other & 0.4950 \\
\hline PG1718 & hypothetical protein & & 0.4955 \\
\hline PG0283 & RND family efflux transporter MFP subunit & Transport and binding proteins: Unknown substrate & 0.4965 \\
\hline PG0001 & chromosomal replication initiation protein & DNA metabolism: DNA replication, recombination, and repair & 0.4984 \\
\hline
\end{tabular}

${ }^{a}$ Locus number, identification and functional classification according to JCVI P.gingivalis genome database

Table 4 Microarray result confirmation by real-time PCR

\begin{tabular}{lll}
\hline Gene & \multicolumn{2}{l}{ Fold increase measured by } \\
\cline { 2 - 3 } & Microarray analysis & Real-time PCR \\
\hline PG1005 & $2.47 \uparrow$ & $12.24 \pm 2.12 \uparrow$ \\
PG1006 & $2.11 \uparrow$ & $11.57 \pm 1.06 \uparrow$ \\
PG1007 & $3.68 \uparrow$ & $24.67 \pm 3.67 \uparrow$ \\
PG1008 & $3.33 \uparrow$ & $28.99 \pm 4.56 \uparrow$ \\
PG1009 & $3.03 \uparrow$ & $27.56 \pm 2.66 \uparrow$ \\
PG1010 & $2.49 \uparrow$ & $19.88 \pm 3.41 \uparrow$ \\
PG0874 & $2.43 \uparrow$ & $18.58 \pm 2.08 \uparrow$ \\
PG1513 & $2.00 \uparrow$ & $15.86 \pm 2.12 \uparrow$ \\
PG0684 & $0.36 \downarrow$ & $0.036 \pm 0.004 \downarrow$ \\
PG0682 & $0.39 \downarrow$ & $0.047 \pm 0.005 \downarrow$ \\
PG1975 & $0.49 \downarrow$ & $0.067 \pm 0.011 \downarrow$ \\
PG1982 & $0.49 \downarrow$ & $0.058 \pm 0.007 \downarrow$ \\
PG2008 & $0.22 \downarrow$ & $0.011 \pm 0.002 \downarrow$ \\
PG0001 & $0.50 \downarrow$ & $0.068 \pm 0.008 \downarrow$ \\
165RNA & - & 1 \\
\hline
\end{tabular}

cell division, and PG1975 encodes hemagglutinin HagC related to pathogenicity of P.gingivalis W83. In addition, PG1982 encodes a CRISPR protein related to CAS1 family. CRISPR/CAS system can protect bacteria against the encroachment by phage, and resist other chromosome genetic material and prevent from the expression of their genes [19-21]. Downregulation of PG1982 suggests a decrease in the defense capability of P.gingivalis W83.

It should be noted that gene expression observed in this study was in mRNA level. As we have known, alterations in mRNA expression are not always consistent with those in protein expression. Therefore, observations in protein level of gene expression will be more convincing. However, it is impracticable to analyze the protein expression of all 64 genes with RNA expression alteration. Moreover, some products of these genes are still hypothetical proteins. Because the inoculated P.gingivalis was cultured outside the rat oral cavity for some days before RNA extraction, the RNA samples cannot exactly reflect the changes in gene expression after inoculation, 
although the results can still indicate which genes are upregulated or downregulated.

\section{Conclusions}

Our study shows that P.gingivalis W83 has pathogenic effects on host, and local inflammatory oral environment alters the gene expression profile of P.gingivalis W83. Products of these upregulated and downregulated genes are mainly related to transposon functions, cell transmembrane transportation, protein and nucleic acid metabolism, energy metabolism, cell division and bacterial pathogenicity. These changes may lead to decreased proliferation and pathogenicity of P.gingivalis W83, and favor themselves to adapt local environment for survival.

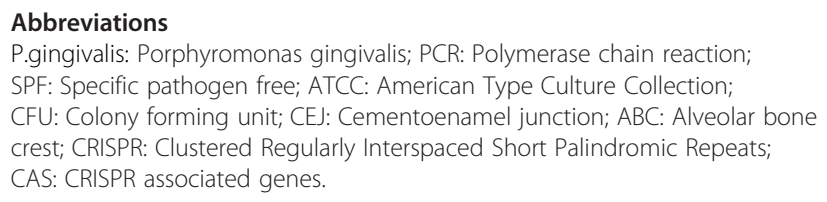

\section{Competing interests}

The authors declare that they have no competing interests.

\section{Authors' contributions}

JZ carried out microarray analysis,analyzed and interpreted the data, and drafted the manuscript. QL performed P.gingivalis W83 culture and inoculation. CLP performed real-time PCR analysis. JCL and HYW were responsible for the isolation and identification of the strain. LST performed alveolar bone loss analysis. YPP designed the study and drafted the manuscript. All authors read and approved the final manuscript.

\section{Acknowledgments}

This work was supported by National Natural Science Foundation of China (No. 81271153).

Received: 2 January 2015 Accepted: 5 May 2015

Published online: 24 May 2015

\section{References}

1. Williams RC. Periodontal disease. N Engl J Med. 1990;322(6):373-82.

2. Aruni AW, Zhang K, Dou Y, Fletcher H. Proteome analysis of coinfection of epithelial cells with Filifactor alocis and Porphyromonas gingivalis shows modulation of pathogen and host regulatory pathways. Infect Immun. 2014;82(8):3261-74.

3. Nissen L, Sgorbati B, Biavati B, Belibasakis GN. Lactobacillus salivarius and L. gasseri down-regulate Aggregatibacter actinomycetemcomitans exotoxins expression. Ann Microbiol. 2014;64:611-7.

4. Kerr JE, Abramian JR, Dao DH, Rigney TW, Fritz J, Pham T, et al. Genetic exchange of fimbrial alleles exemplifies the adaptive virulence strategy of Porphyromonas gingivalis. PLoS One. 2014;9(3), e91696.

5. Baker PJ. The role of immune responses in bone loss during periodontal disease. Microbes Infect. 2000;2(10):1181-92.

6. Anaya-Bergman C, Rosato A, Lewis JP. Iron- and hemin-dependent gene expression of Porphyromonas gingivalis. Mol Oral Microbiol. 2015;30(1):39-61

7. Phillips P, Progulske-Fox A, Grieshaber S, Grieshaber N. Expression of Porphyromonas gingivalis small RNA in response to hemin availability identified using microarray and RNA-seq analysis. FEMS Microbiol Lett. 2014;351(2):202-8.

8. Moon JH, Lee JH, Lee JY. Microarray analysis of the transcriptional responses of Porphyromonas gingivalis to polyphosphate. BMC Microbiol. 2014;14:218.

9. Azelmat J, Larente JF, Grenier D. The anthraquinone rhein exhibits synergistic antibacterial activity in association with metronidazole or natural compounds and attenuates virulence gene expression in Porphyromonas gingivalis. Arch Oral Biol. 2015;60(2):342-6.
10. Yoshimura M, Ohara N, Kondo Y, Shoji M, Okano S, Nakano Y, et al. Proteome analysis of Porphyromonas gingivalis cells placed in a subcutaneous chamber of mice. Oral Microbiol Immunol. 2008;23(5):413-8.

11. Baker PJ, Dixon M, Roopenian DC. Genetic control of susceptibility to Porphyromonas gingivalis-induced alveolar bone loss in mice. Infect Immun. 2000;68(10):5864-8.

12. Zhang Z, Saier Jr MH. Transposon-mediated adaptive and directed mutations and their potential evolutionary benefits. J Mol Microbiol Biotechnol. 2011;21(1-2):59-70.

13. Wheeler BS. Small RNAs, big impact: small RNA pathways in transposon control and their effect on the host stress response. Chromosome Res. 2013;21(6-7):587-600.

14. Arnault C, Dufournel I. Genome and stresses: reactions against aggressions, behavior of transposable elements. Genetica. 1994;93(1-3):149-60.

15. Hendrickson EL, Xia Q, Wang T, Lamont RJ, Hackett M. Pathway analysis for intracellular Porphyromonas gingivalis using a strain ATCC 33277 specific database. BMC Microbiol. 2009;9:185.

16. Xia Q, Wang T, Taub F, Park Y, Capestany CA, Lamont RJ, et al. Quantitative proteomics of intracellular Porphyromonas gingivalis. Proteomics. 2007;7(23):4323-237.

17. Park Y, Yilmaz O, Jung IY, Lamont RJ. Identification of Porphyromonas gingivalis genes specifically expressed in human gingival epithelial cells by using differential display reverse transcription-PCR. Infect Immun. 2004;72(7):3752-8.

18. Létoffé $S$, Delepelaire $P$, Wandersman C. Free and hemophore-bound heme acquisitions through the outer membrane receptor HasR have different requirements for the TonB-ExbB-ExbD complex. J Bacteriol. 2004;186(13):4067-74.

19. Pourcel C, Salvignol G, Vergnaud G. CRISPR elements in Yersinia pestis acquire new repeats by preferential uptake of bacteriophage DNA, and provide additional tools for evolutionary studies. Microbiology. 2005;151(Pt 3):653-63.

20. Haft DH, Selengut J, Mongodin EF, Nelson KE. A guild of 45 CRISPRassociated (Cas) protein families and multiple CRISPR/Cas subtypes exist in prokaryotic genomes. PLoS Comput Biol. 2005;1(6), e60.

21. Grissa I, Vergnaud G, Pourcel C. The CRISPRdb database and tools to display CRISPRs and to generate dictionaries of spacers and repeats. BMC Bioinformatics. 2007;8:172.

\section{Submit your next manuscript to BioMed Central and take full advantage of:}

- Convenient online submission

- Thorough peer review

- No space constraints or color figure charges

- Immediate publication on acceptance

- Inclusion in PubMed, CAS, Scopus and Google Scholar

- Research which is freely available for redistribution 